\title{
CONFLITOS VIVENCIADOS POR PROFISSIONAIS DE ENFERMAGEM E IDOSAS EM UMA INSTITUIÇÃO DE LONGA PERMANÊNCIA
}

Caren da Silva Jacobi; Universidade Federal de Santa Maria; cahjacobi@gmail.com Jamile Laís Bruinsma; Universidade Federal de Santa Maria; bruinsmajamile@gmail.com Marinês Tambara Leite; Universidade Federal de Santa Maria; tambaraleite@yahoo.com.br Matheus Souza Silva; Hospital Universitário Dr. Miguel Riet Corrêa Jr.; matheussouzaenf@gmail.com Carolina Backes; Universidade Federal de Santa Maria; karolbackes@hotmail.com Eliane Raquel Rieth Benetti; Hospital Universitário de Santa Maria; elianeraquelr@yahoo.com.br Margrid Beuter; Universidade Federal de Santa Maria; margridbeuter@gmail.com

\section{RESUMO}

Introdução: residir em Instituição de Longa Permanência para Idosos (ILPI) exige adequação as regras e espaços, e estabelecimento de novas relações. Tais situações podem gerar conflitos entre residentes ou com profissionais da instituição. Objetivo: identificar situações de conflitos interpessoais de idosas institucionalizadas vivenciados por profissionais de enfermagem. Método: pesquisa qualitativa com 15 profissionais de enfermagem trabalhadores de ILPI. A coleta dos dados ocorreu por meio de entrevista semiestruturada e, após os dados foram analisados conforme a análise de conteúdo temática da proposta operativa de Minayo. Resultados: as situações de conflitos vivenciadas por profissionais ocorreram quando as idosas se apossavam de objetos pessoais de outras residentes, como bonecas ou nas refeições devido a padronização de horários e alimentos nem sempre aceitos por algumas residentes. Há conflitos ao acreditarem que algumas residentes são beneficiadas na quantidade de comida pelos funcionários, elas entravam em atrito com os profissionais requerendo a mesma porção de refeição. Quando as idosas apresentavam comportamentos alterados pelo quadro demencial/psiquiátrico e tinham atitudes contestadas pelos profissionais ou por outras residentes aconteciam conflitos. Os comportamentos envolviam despir-se em frente as demais,confusões de ideias, alucinações ou recusa de medicações, higiene corporal ou refeições. Algumas idosas sobrepunham-se às outras, com atitudes de arrogância, sendo identificadas como líderes. A presença de diferentes personalidades no mesmo espaço suscitou tensões. Conclusão: situações de conflito ocorrem no cotidiano de profissionais e idosas de uma ILPI motivados por atividades profissionais ou atitudes das residentes. Destaca-se a importância de compreender os conflitos para promover o manejo adequado destas situações.

Palavras-chave: Conflito psicológico; Idoso; Instituição de longa permanência para idosos; Enfermagem geriátrica. 